\title{
The Degradation of the Bafut-Ngemba Forest Reserve Revisited: A Spatio-temporal Analysis of Forest Cover Change Dynamics
}

\author{
Josephine Akenji Maghah, Reeves Meli Fokeng* \\ Department of Geography and Planning, Faculty of Arts, The University of Bamenda, Bambili, Cameroon \\ Email address: \\ akenjitulis@gmail.com (J. A. Maghah),rfokeng@yahoo.com (R. M. Fokeng) \\ ${ }^{*}$ Corresponding author \\ To cite this article: \\ Josephine Akenji Maghah, Reeves Meli Fokeng. The Degradation of the Bafut-Ngemba Forest Reserve Revisited: A Spatio-temporal \\ Analysis of Forest Cover Change Dynamics. American Journal of Remote Sensing. Vol. 9, No. 1, 2021, pp. 33-41. \\ doi: 10.11648/j.ajrs.20210901.14
}

Received: February 17, 2021; Accepted: March 3, 2021; Published: March 26, 2021

\begin{abstract}
Globally, forest reserves are created with a premier objective to conserve important biodiversity and to ensure ecosystems services provision. Unfortunately, forest reserves in the global south are threatened by the tremendous rise in human numbers and the unsustainable exploitation of forest resources. This is the problem facing protected areas (PAs), including forest reserves in Cameroon. The Bafut-Ngemba Forest Reserve (BNFR) is just a case in point of the many transformed and ecological twisted forest reserves in the Western Highlands of Cameroon. The BNFR is no biodiversity paradise as the humanisation of the reserve has taken an unprecedented toll in recent times. The study updated forest cover changes within the reserve from previous studies spanning across 2010-2021 as a baseline data towards the effective design of sustainable forest conservation planning. Satellite remote sensing employing high resolution ASTER $(15 \mathrm{~m})$ and real-time Google Earth images were used to assess the forest cover dynamics. Between 2010 and 2015, forest loss was mild, either 27.135ha. From 2015-2021, in just less than 6 years, 696.397ha of forest cover was lost. For the entire study period (20102021), at total of 723.532ha of forest is estimated to have been lost. Forest loss in the BNFR is linked to some four anthropogenic stressors; farmland encroachment, eucalyptus colonisation, wood harvesting and cattle grazing alongside interannual fires used for pasture regeneration and rangeland management. Conservation efforts are urgently needed should the remaining threatened biodiversity, mostly avifauna is to be protected in line with monitoring progress to global targets and SDG 15.1.1.
\end{abstract}

Keywords: Forest Reserves, Forest Cover Changes, Forest Loss, Anthropogenic Stressors, Conservation

\section{Introduction}

Forests are vital for the sustainability of ecosystems and the services they provide to humankind. It is widely acknowledged that forests and trees simultaneously provide a wide range of socio-economic and environmental benefits and values to humankind [1]. Forests cover about $45.6 \%$ of Cameroon's national territory, approximately $21,245,000$ hectares [2]. The country's forestland is said to be declining in the past years. This decline threatens all the forest resources: trees, flora and fauna. With high population growth rates, growing poverty, public corruption, and other similar ills, the fate of Cameroon's forest is further jeopardized [3]. Recent estimates by FAO [4] show a decrease in forest land area shrinking down to 19036000 ha. Based on findings by de Wasseige et al. [5], the gross rate of deforestation in Cameroon between 1990 and 2005 increased; while the period, $1990-2000$ recorded $0.10 \%$ with the period of $2000-2005$ recording $0.17 \%$. It is estimated that between 1990 and 2010, Cameroon lost 440000 ha (18.1\%) of forest cover at an average rate of 220000 ha $(0.90 \%)$ annually [6]. Illegal logging activities are greatly responsible for such rise in deforestation [7], as well as increasing pressure from other sectors such as commercial and subsistence agriculture, mining, hydropower, and infrastructure [8]. Other reasons include urban expansion due 
to the rural exodus and population growth [9]. Mountains support about one quarter of world's terrestrial biodiversity and include nearly half of the world's biodiversity "hotspots", often sanctuaries for plants and animals longgone from the more transformed lowlands [10].

As a first step towards halting and reversing biodiversity loss, the Convention of Biological Diversity (CBD) recommended the creation of protected areas. According to [11], 45 percent of the 2.2 million hectares of Cameroon's forestland was designated as protected areas (PAs) prior to the signing of the CBD in 1992. [12], reported that Cameroon had a total of 56 forest reserves in 2015 wrapping up to 492 166 ha. However, before the signing of the CBD, some PAs existed as far back the colonial era. This is the case with the Bafut-Ngemba Forest Reserve (BNFR). The British colonial government created the Bafut-Ngemba Native Authority Forest Reserve (BNNAFR) in 1953 in the Bamenda Highlands with the objectives of protecting the native montane forest and its rich biodiversity. Today the BNFR has become an ecological shadow of itself [13], and/or an ecological refugia. According to Cameroon's forestry, wildlife and fisheries regulations of 1994, the BNFR is a private property of the state and so it is forbidden to: clear any part of the forest; to set fire within; exploitation of such an area is forbidden; public access to this area may be regulated or forbidden and since this area is supposed to be reserved solely for forestry and wildlife habitat, customary right may be limited if they are contrary to the purpose of such an area. In spite of these regulations, it has been noticed that with the onset of the economic crisis in the late 1980s, things took a different dimension in Cameroon in general and the areas surrounding the forest reserve in particular [14]. This economic meltdown couple with tremendous growth of population of the adjacent communities amongst other anthropogenic stressors have fuelled uncontrolled deforestation and the continuous encroachment and transformation of the BNFR by crop farmers and money yielding eucalyptus plantation farmers.

The degradation of this historic forest reserve has been variably reported [13-15]. The limited updates on forest cover loss estimates and/or state of forest resources within the reserve makes the design of conservation efforts problematic. The rate of forest loss has been quantified by Takem-Mbi [14] for the periods of 1978 and 2006 using passive remote sensing. [14] revealed a $37 \%$ forest loss between 1978 and 2006. Recent studies by Fogwe et al. [13] left out detail estimates of present forest cover as it focused on the drivers of forest loss and the ecological transformation of the BNFR by exotic eucalyptus.

Thus, the assessment of forest cover loss in this forest reserve forms a baseline data to understanding the rates and intensity of large scale deforestation in non-demarcated and/or protected forested areas and a guide towards forest conservation planning. The study used the BNFR as a case study to assess the rate and intensity of montane forest cover loss on the protected areas in the Bamenda Highlands, which forms proxy data for drafting biodiversity conservation plans and effective forest management options for areas undergoing tremendous increase in human numbers.

The Bafut-Ngemba Forest Reserve wrapping some 3684ha of highland $(1,742-2,612 \mathrm{~m}$ above sea level) is located on the north eastern flank of the Bamenda Highlands (Figure 1).

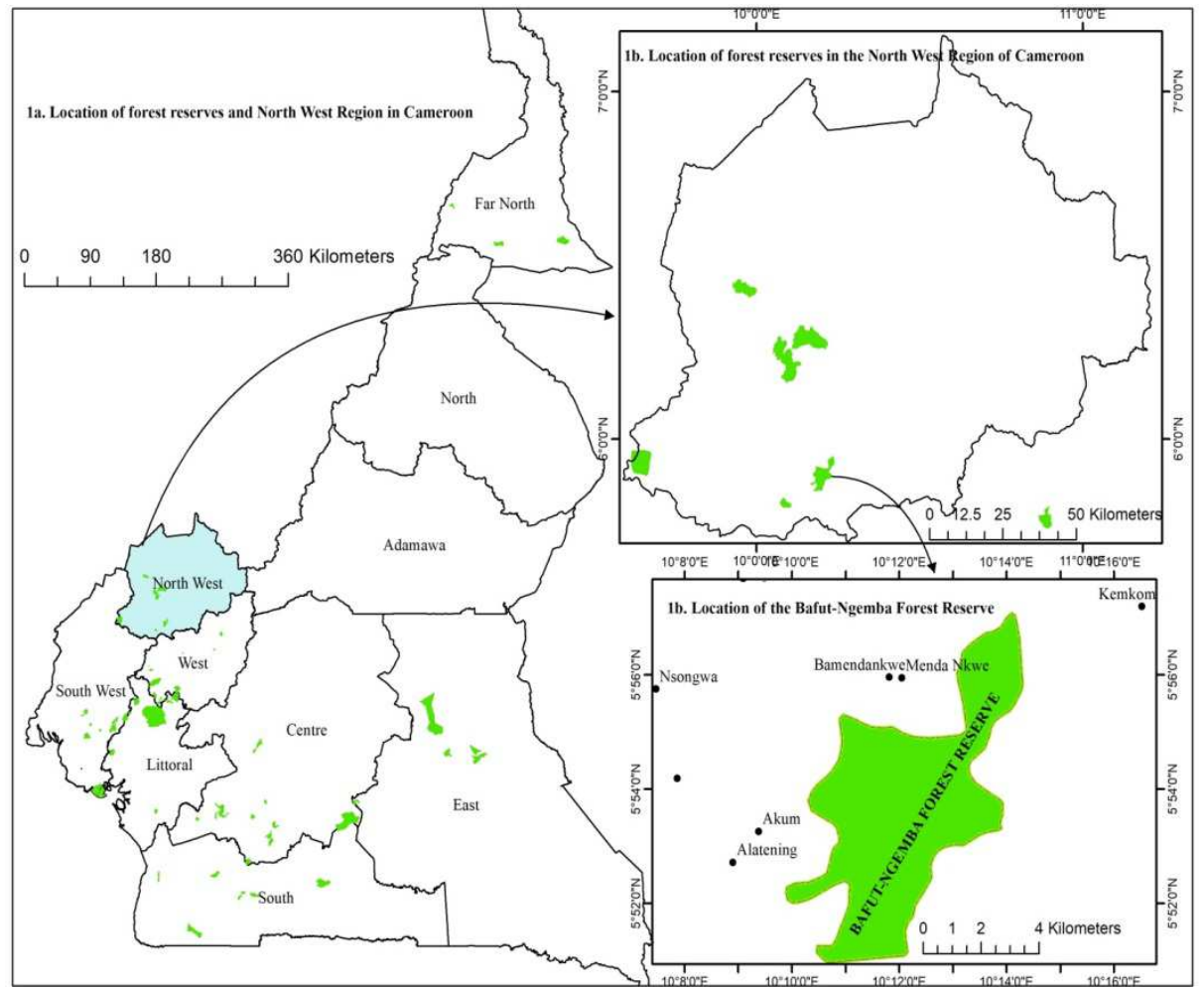

Figure 1. Location of study area. 
This reserve is crossed by a number of rivers and is a catchment area for the water that is used by the population of Bamenda [14]. Lake Awing which is recognised as an international touristic site and a potential Ramsar site is located in this reserve (Figure 2). As a major geo-hydrological divide for streams, the drainage network shows a radial pattern (Figure 2).
The forest reserve which is expected to be a save heaven for some endemic biodiversity has been highly degraded. Concerning the avifauna, Bannerman's Turaco and Banded Wattle-eye are commonplace. In the early morning the rasping call of Bannerman's Turaco can be heard from isolated valleys [15] within the forest reserve.

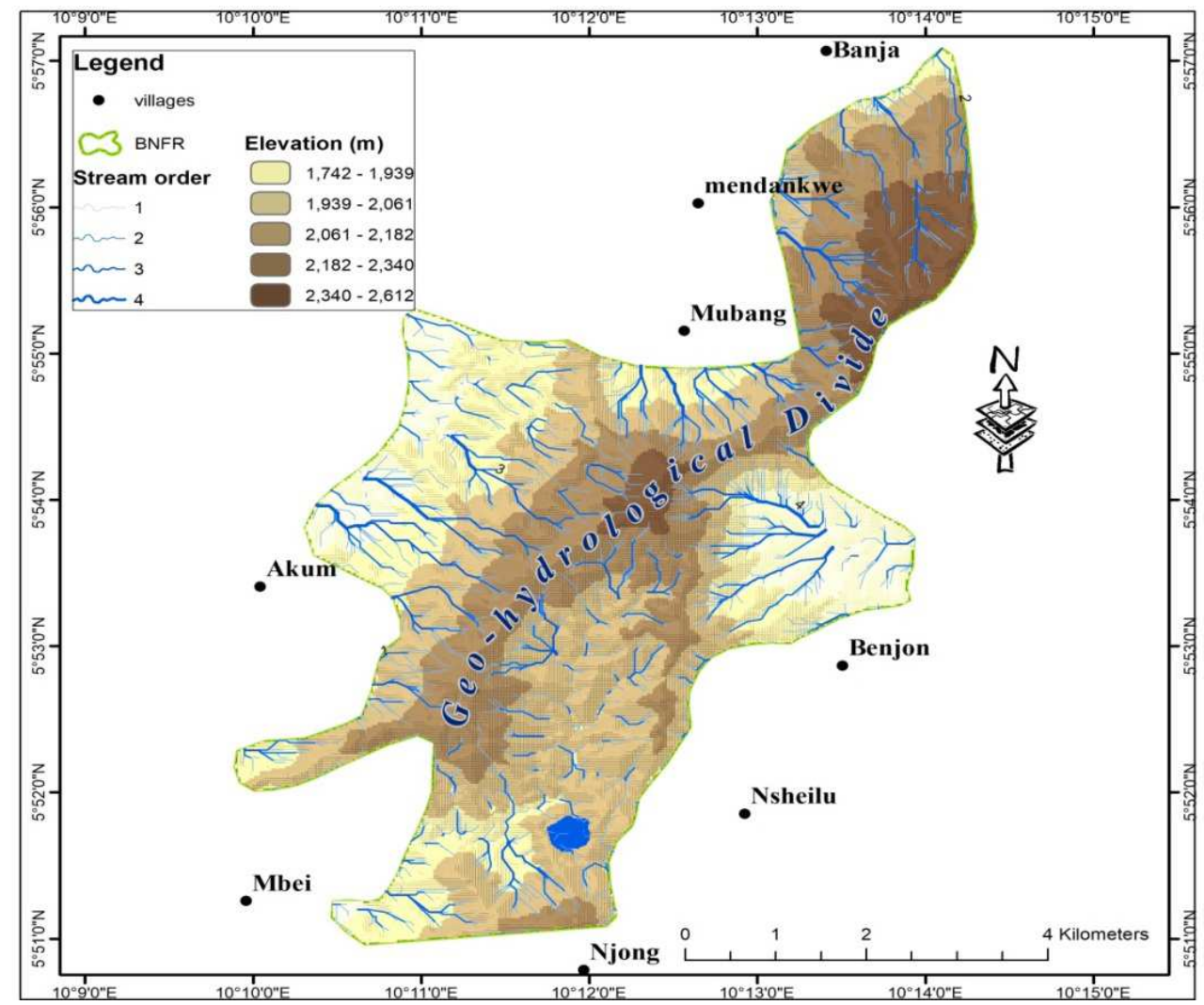

Figure 2. Relief and drainage of the BNFR.

According to a report by Nsoh et al. [16], this reserve harbours monkeys, chimpanzees, and antelopes amongst other species. The main adjacent communities include, Alatening, Akum, Santa-Awing, Santa-Njong, Menda-Nkwe and Bangshie. This has constituted the main threat to forest resources within the reserve.

\section{Materials and Methods}

\subsection{Study Period}

Based on studies of [14] which quantified forest cover loss for over 28 years (1978-2006), we revisited the forest cover change dynamics from (2010-2021), for a three time-scale (2010, 2015, 2021). This will go a long way to monitor progress in SDG 15.1.1. (forest area as a proportion of total land area) and SDG 15.3.1 (proportion of land that is degraded over total land area). The UNCCD [17] recommendations for monitoring progress in SDG 15.3.1 involves the assessment of three main indicators; land productivity dynamics, land cover change, and soil organic carbon stocks. This study is thus anchored on sub-indicator 2 (land cover change) analysis to update forest cover loss within BNFR.

Table 1. Remote sensing data used in the study.

\begin{tabular}{llllll}
\hline S/N & Sensor & Resolution $(\mathbf{m})$ & Acquisition date & Spacecraft operator & Source \\
\hline 1 & ASTER & 15 & $2010-09-15$ & METI \& NASA & USGS \\
2 & ASTER & 15 & $2015-06-25$ & METI \& NASA & USGS \\
3 & ASTER & 15 & $2021-01-12$ & METI \& NASA & USGS \\
5 & AW3D30 & 30 & 2019 & JAXA & JAXA \\
6 & MODIS & $1 \mathrm{~km}$ (fire dots) & $2000-2020$ & NASA & FIRMS \\
\hline
\end{tabular}

Note: METI: Japanese Ministry of Trade, NASA: National Aeronautics and Space Agency, JAXA: Japanese Aerospace Agency, FIRMS: Fire Information for Resource Management System 


\subsection{Image Acquisition and Processing}

To enhance precision in forest cover change detection, the study employed high resolution ASTER images at $15 \mathrm{~m}$ resolution composites for over 11 years $(2010,2015$ and 2021) obtained from the US Geological Survey (USGS) website (Table 1).

Image radiometric and atmospheric corrections to calibrate the pixel values and/ correct for errors was done using the top-of-atmospheric (TOA) reflectance Dark Object Subtraction (DOS1) Method in QGIS 3.14 Semi-Automatic Classification Plugin. The supervised classification technique was used to classify the calibrated images for land cover/use classification. The accuracy of attributed land cover/use classes was checked with real-time and archived Google Earth Images as well as toposheet of Bamenda (Bafoussam 3c). The Moderate Resolution Imaging Spectroradiometer (MODIS) at $1 \mathrm{~km}$ spatial resolution fire product (MCD14ML) was used in a later stage to capture fire dynamics within the reserve as one of the main anthropogenic stressors driving forest loss and degradation.

\section{Results and Discussion}

\subsection{Forest Cover Changes (1978-2021)}

The study of Takem-Mbi [14] estimated 2946ha and 1373ha of forest cover for the periods of 1978 and 2006 respectively. The findings of the above research showed a declining trend in forest cover. Table 2 shows forest cover estimates over 11 years (2010-2021).

Table 2. Land cover/use and forest cover estimates from 2010-2021.

\begin{tabular}{llllll}
\hline \multirow{2}{*}{ Land cover } & Area (ha) & \multicolumn{3}{c}{ Change (ha) } \\
\cline { 2 - 6 } & $\mathbf{2 0 1 0}$ & $\mathbf{2 0 1 5}$ & $\mathbf{2 0 2 1}$ & $\mathbf{2 0 1 0 - 2 0 1 5}$ & $\mathbf{2 0 1 5 - 2 0 2 1}$ \\
\hline Forest & 1754.145 & 1727.01 & 1030.613 & -27.135 & -696.397 \\
Farmlands & 1173.353 & 616.14 & 888.57 & -557.213 & 272.43 \\
Grassland/shrubs & 333.18 & 1146.1 & 1333.612 & 812.92 & -284.783 \\
Water bodies & 15.1425 & 16.92 & 15.93 & 1.76 & 187.512 \\
Bare surfaces & 378.2025 & 149.58 & 378.45 & -228.623 & -0.99 \\
Settlement & 1.573 & 2.16 & 3.16 & 0.587 & 228.87 \\
Total & 3684 & 3684 & 3684 & - & 0.788 \\
\hline
\end{tabular}

The study period showed intense dynamics in forest cover and other land cover/uses. As compared to the estimates of Takem-Mbi [14] in 2006 (1373ha), there was somewhat an improvement in forest cover by 2010 (either 381.145ha), evidently steaming from replacement of natural forest with commercial eucalyptus plantations (Figure 6). From 2010 to
2021, a total of $-723.532 \mathrm{ha}$ (either $723.532 \mathrm{ha}$ ) of forest is lost. Farmlands showed a rise and fall trend as well as bare surfaces (Figure 3). In some instances, changes in area under bare surfaces is explained by degradation and forest harvesting (both natural and planted eucalyptus forest) (see Figure 6, Photo A).

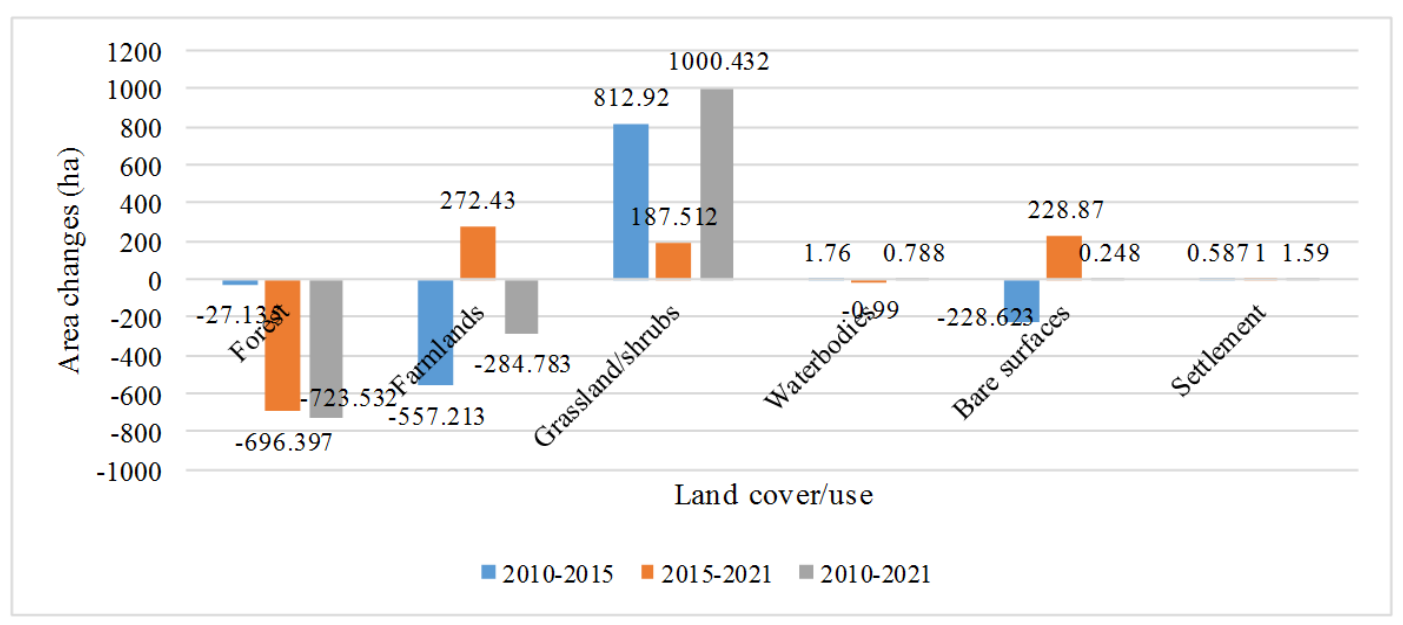

Figure 3. Trend changes in land cover/use in the study area.

Grasslands/shrubs also showed rise and fall swings during the study period. The gain in grassland cover (Table 2) between 2010-2021 (1000.432ha) is also partly explained by deforestation and forest conversion and grazing pressure within the forest. The method of grazing is the free grazing type under common pool resources. Such unguided grazing uses year-in-year out fires during the dry seasons to regenerate pastures and manage rangeland insect infestation.
[14] reported the presence of some six sedentary graziers around the forest reserve. Fire is thus a driver of forest cover loss and transformation of the reserve. Fire dynamics over a 20 years period in the reserve is well established using MODIS active fire product (MCD14ML).

Figure 4 shows spatial dynamics and changes in land cover/use in the forest reserve from 2010-2021. The most dynamic land cover is forest, showing a declining trend over 
space (Figure 4) and time (Figure 5).

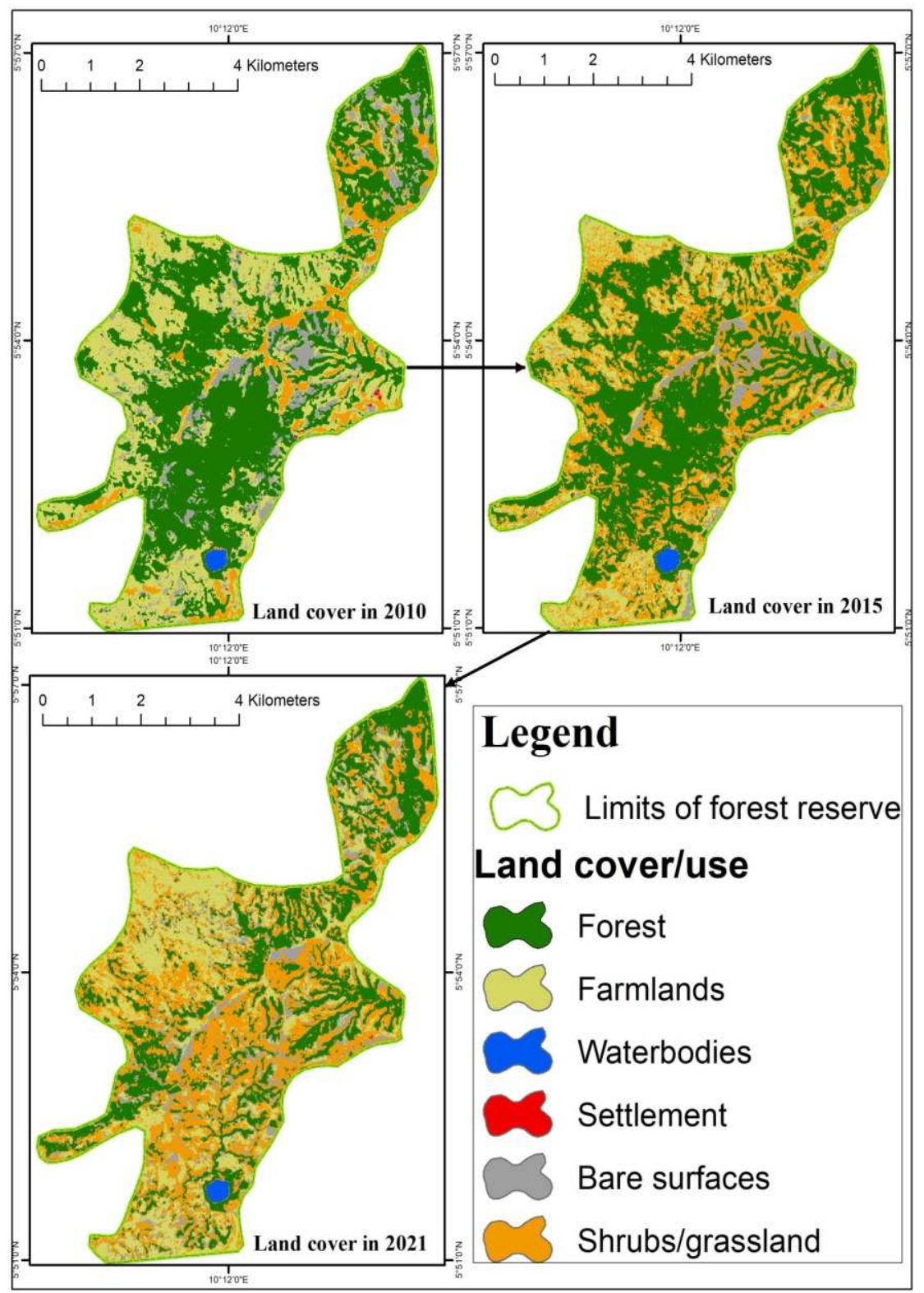

Figure 4. Land cover/use change spatial dynamics (2010-2021) in the BNFR.

An analysis of forest cover transition (2010-2021) shows a downward transition within the reserve (Figure 5).

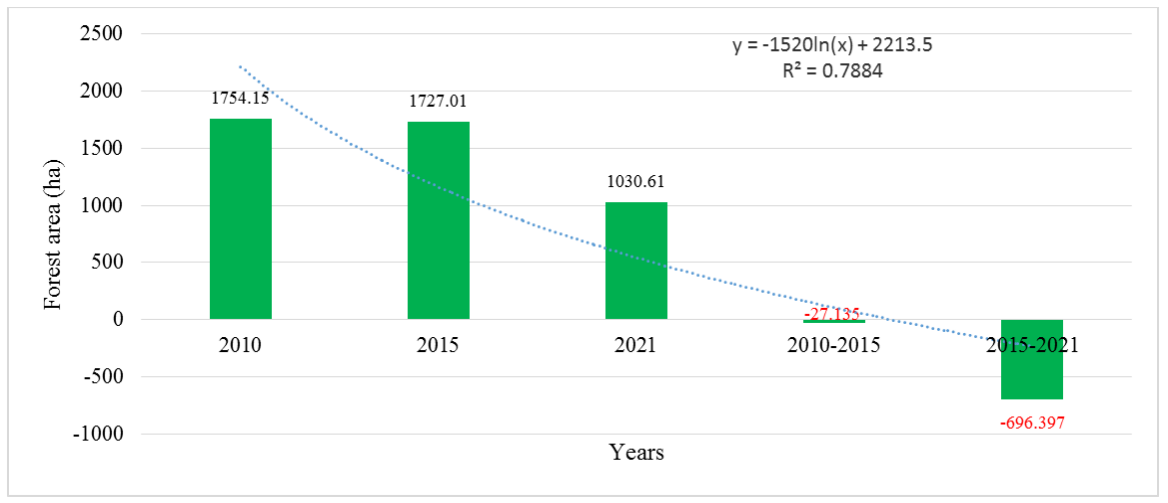

Figure 5. Forest cover changes-time relationship for the BNFR. 
For the 11 years period, forest cover showed a declining trend. Between 2010 and 2015, forest loss was mild, either 27.135ha of forest loss. From 2015-2021, in just less than 6 years, -696.397ha (either 696.39ha) of forest cover was lost (Figures 3, 4, 5 and 7). The trend in forest decline is continuous and significant $\left(\mathrm{R}^{2}=0.7884\right)$, see figure 5 . Forest area is being transformed for farmlands, grazing lands as well as degraded by illegal fuel wood exploitation and grazierinduced fires within the reserve.

\subsection{Anthropogenic Stressors in the BNFR}

Some four anthropogenic stressors are identified as the main drivers of forest cover loss in the BNFR amongst other determinants.

\subsubsection{Farmland Encroachment}

The reserve is encroached by commercial crop farmers. These include market gardening crops (cabbages, tomatoes, carrots, green beans, just to mention but these) and other income generating crops like Irish potatoes. The inhabitants of Mile 12, Santa, Akum and some who come as far as
Bamenda have transformed this part of the reserve for the practiced of this activity [14]. This is not only to serve the food needs of the nearby Bamenda Urban Area but the rest of Cameroon's metropolises. This has also been facilitated by increase accessibility to the reserve through rural road construction (Figure 6). Rural road network development has been reported to drive forest cover loss in most of the Congo Basin. Slash-and-burn agriculture, commercial farming and the development of infrastructure to open up the forest zones together with the construction of secondary agricultural roads are the main causes of deforestation [9].

\subsubsection{The Colonisation of the Reserve by Exotic Eucalyptus}

The transformation of the Bamenda Highlands with exotic eucalyptus is becoming the norm rather than the exception. The natural montane forest has been cleared and its replacement with quick money yielding eucalyptus plantations (Figure 6). This is an environmentally unfriendly species with far reaching effects on surface and underground water resources on the highlands. The Eucalyptus colonisation of the BNFR has been reported by Fogwe et al. [13].

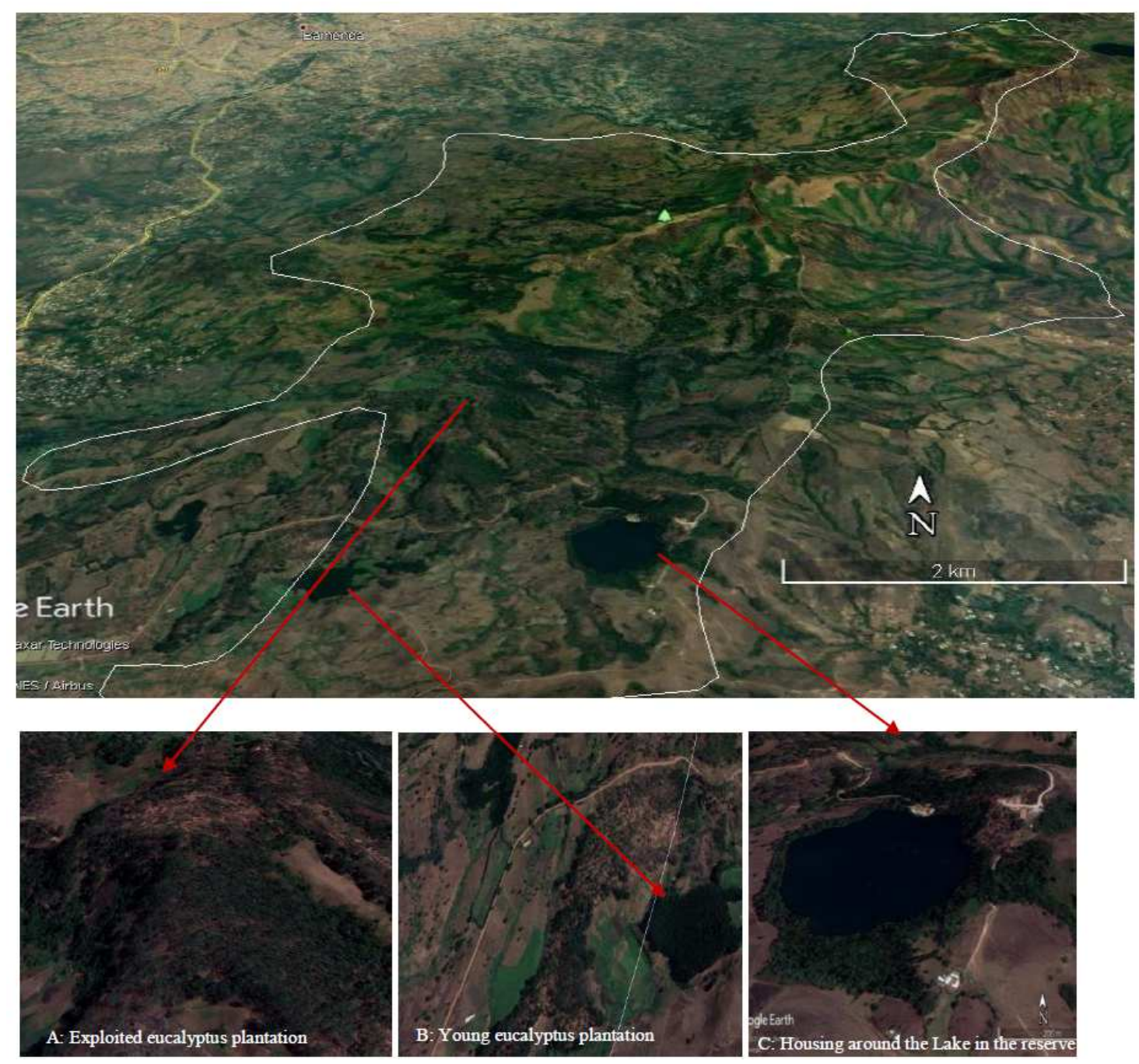

Source: Google Earth (2021)

Figure 6. Real-time Google Earth Images showing anthropogenic stressors on the BNFR. 
The development of road network across the reserve from Santa Mile 12 through Santa-Awing to Santa-Njong has increased the rate of forest resources exploitation and depletion. The transformation of the reserve by quick money yielding eucalyptus tree farming is also partly driven by this increase accessibility within the highlands (Figure 6).

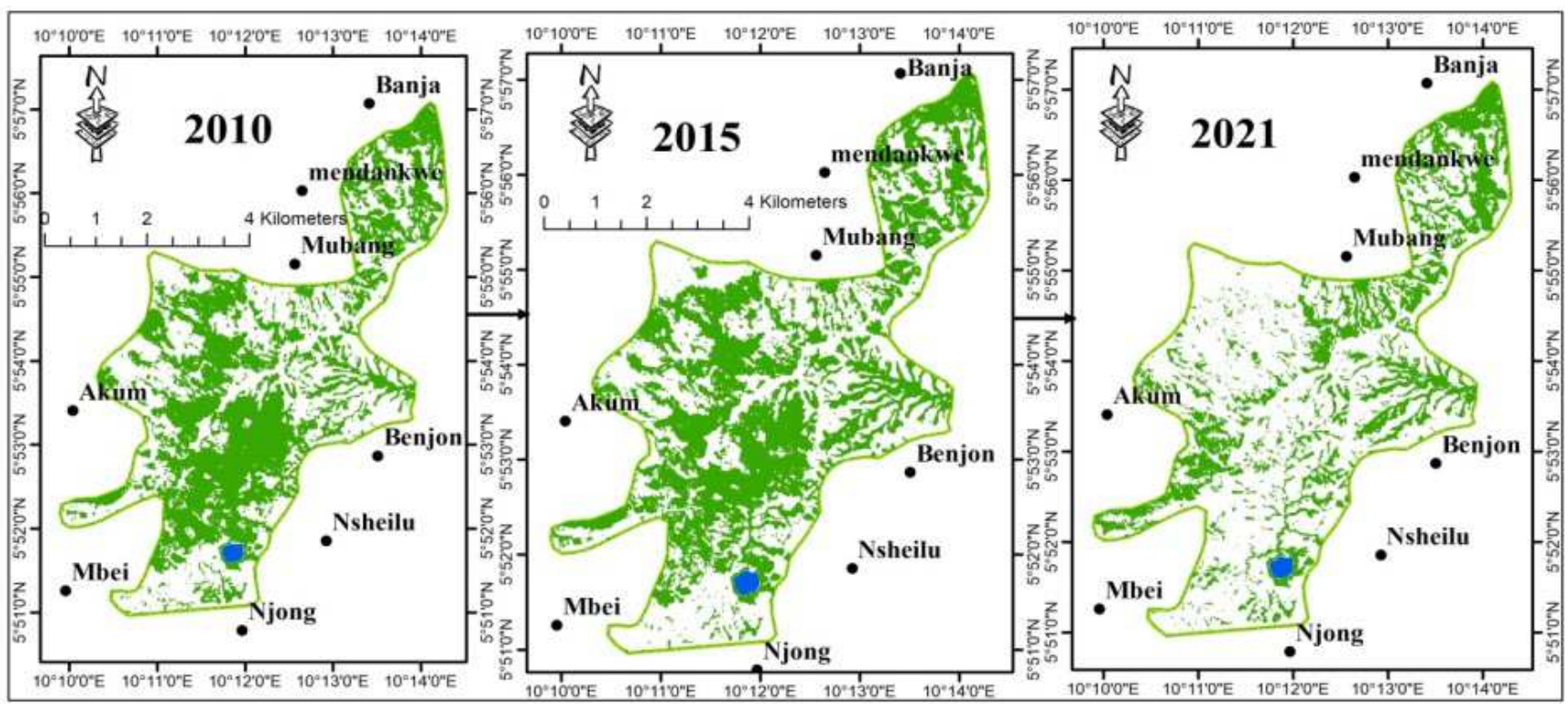

Figure 7. Forest cover change dynamics and transition in the BNFR.

\subsubsection{Wood Harvesting}

Illegal wood exploitation in the reserve is amongst the main drivers of forest loss. The logging for economic returns within this forest, has led to continuous decline and fragmentation of the intact natural forest. Such wood exploitation is to meet the fuel needs of the rising burgeoning nearby communities and the Bamenda Metropolis. Takem-Mbi [14] confirmed that the harvesting of fuel wood both for domestic and commercial purposes is another non negligible cause for the change witnessed on the reserve from 1978 to 2006 . Fuel wood and charcoal constitute the main source of income for approximately $80 \%$ of the interviewed population of Mendankwe and $60 \%$ of youths interviewed are equally involved in these activities which are concentrated in the northwest section of the forest reserve [14]. This activity is still ongoing and to a greater extent as prior to the loss of the natural forest, natives have resorted to planting of fast money yielding eucalyptus trees, which is yet an environmentally unsound reforestation strategy with negative feedback loops on the surface and underground water resources. Many researchers [18-24, 13], have reported montane forest loss in the Bamenda Highlands being partly linked to household and commercial fuel wood exploitation. The exploited wood is destined for the Bamenda Metropolis in majority as Sop [25] reported that fuel wood commercialised in Bamenda is from outside the metropolis and nearby Highlands. Atyi et al. [26] pointed out that over $80 \%$ of the people in Cameroon depend entirely on wood-energy for household energy supply.

\subsubsection{Cattle Grazing and the Inter-Annual Use of Fires for Pasture Regeneration}

Cattle grazing and use of fires for rangeland management is now driving long-term changes in grassland ecosystems. The Bamenda Highlands is extensively being used for grazing by sedentary and transhumant Mbororo. Because the graziers depend on natural pastures, the use of fires in pasture regeneration is the main way of rangeland management. The inter-annual use of fires for rangeland management though beneficial to the graziers, has attendant effects on the vegetation as well as emission of greenhouse gases. The effects of grazing pressure on forest reserves have been widely reported in the Western Highlands of Cameroon [20, 27, 7]. Grazing also showed to have far reaching impacts on protected areas in Cameroon as raised by Mbanga and Gonne [28] in the Benue, Faro, Bouba Ndjidda Complex, (FBBNC) in the North region of Cameroon. Takem-Mbi [14] revealed that six cattle herd owners live in and around the BafutNgemba Forest Reserve and are using it as a grazing ground alongside the use of fires to regenerate pasture for their herds. A total of 153 active fires were captured by the MODIS active fire product in 20 years (2000-2020) (Figure $8)$.

The relationship between fire and deforestation, both complete clearing and selective logging, has been well documented [29, 30, 31]. 


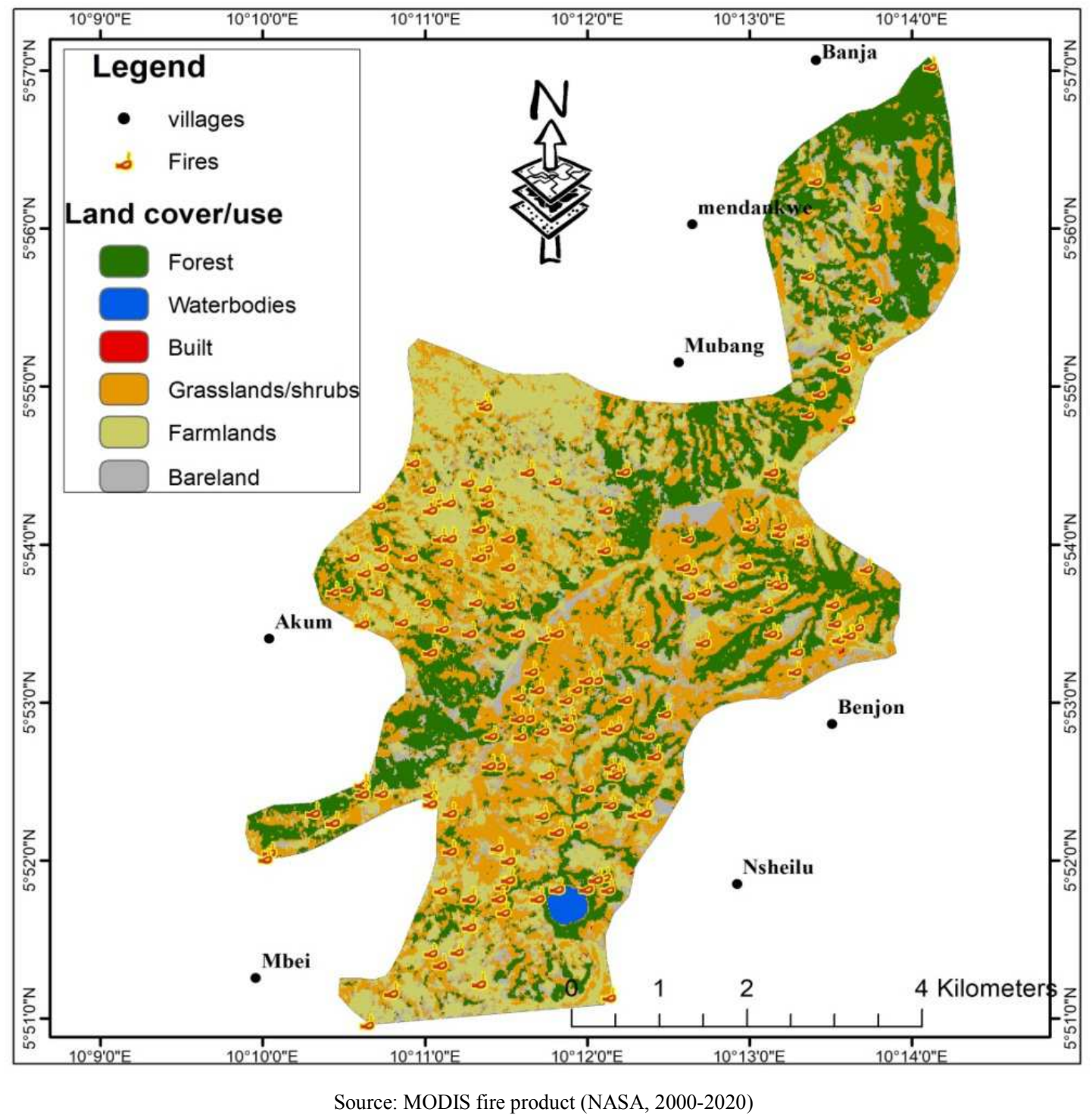

Figure 8. Spatial distribution of active fires over different land cover/use in the BNFR (2000-2020).

\section{Conclusions and Recommendations}

The degradation of the historic BNFR has been revisited and the present state of forest resources exposed. Everything being equal, forest cover loss will continue unabated if sustainable forest conservation strategies and effective forest management options are not designed and implemented within the shortest time frame. The disappearance of the forest reserve will have far reaching repercussions on the water supply in the surrounding nearby communities. Water supply quantity and quality in the nearby metropolitan Bamenda has been reported not to reach desired objectives. This problem will rise in the near future if montane forest degradation is not reversed. As a first approximation to meeting the global sustainable goal targets (SDGs 6, 11, 13, and 15), sustainable land management practices of grazing, farming and forest resources exploitation and reforestation (with water retaining trees) are palliatives to addressing the problem.

\section{References}

[1] Foahom, B. (2001). Biodiversity Planning Support Programme Integrating Biodiversity into the Forestry Sector Cameroon Case Study. Paper prepared for an international workshop on "Integration of Biodiversity in National Forestry Planning Programme" held in CIFOR Headquarters, Bogor, Indonesia on 13-16 August 2001.

[2] Food and Agriculture Organization (2005). Global forest resources assessment 2005. Progress towards sustainable forest management. FAO forestry paper 147. Food and Agriculture organization of the United Nations, Rome.

[3] Fonjong, L. (2007). Managing deforestation in Anglophone Cameroon: are NGOs pacesetters? International Journal of Environmental Studies, 63, (5) Africa - Changing How? https://doi.org/10.1080/00207230600963619.

[4] FAO

(2014).

FAOSTAT. 
[5] de Wasseige, C., Flynn, J., Louppe, D., Hiol, H. F., Mayaux, Ph. (2014). The forest of the Congo Basin - State of the forest 2013. Weyrich, Belgium.

[6] REDD Desk. (2013). Statistics for Cameroon. Accessed at http://theredddesk.org/countries/cameroon/statistics on the 21 st June 2017.

[7] Fokeng, M. R., Forje, G. W., Meli, M. V., Nyuyki, B. B. (2020). Multi-temporal forest cover change detection in the Metchie-Ngoum Protection Forest Reserve, West Region of Cameroon. The Egyptian Journal of Remote Sensing and Space Science, 23, (1), 113-124.

[8] WRI (online). https://www.wri.org/ourwork/project/governance-forests-initiative/cameroon.

[9] Tchatchou, B., Sonwa, D. J, Ifo S, Tiani A. M. (2015). Deforestation and forest degradation in the Congo Basin: State of knowledge, current causes and perspectives. Occasional Paper 144. Bogor, Indonesia: CIFOR.

[10] UNEP (2010). Mountain Biodiversity, the Secretariat of the Convention on Biological Diversity, [on line] www.cbd.int/mountain.

[11] Takem-Mbi, B. M., Kaffo, C., Fish, L. (2010). 'Protected area' coverage in Cameroon on the eve of the Convention of Biological Diversity 2010 target. International Forestry Review, 12, (3), 231-239.

[12] MINFOF \& WRI. (2015). Interactive Forest Atlas of, Cameroon.

[13] Fogwe, Z. N., Tume, S. J. P., Fouda, M. (2019). Eucalyptus Tree Colonization of the Bafut-Ngemba Forest Reserve, North West Region, Cameroon. Environment \& Ecosystem Science, 3 (2), 12-16.

[14] Takem-Mbi, B. M. (2013). Assessing forest cover change in the Bafut-Ngemba Forest Reserve (BNFR), North West Region of Cameroon using remote sensing and GIS. International Journal of Agricultural Policy and Research, 1 (7), 180-187.

[15] Mills, M., \& Cohen, C. (2004). Birding Cameroon, part 2. Southern Cameroon: forests, low to lofty. ABC Bulletin, 11 (1), 51-58.

[16] Nsoh F., Afese A. F, Neba C. (2006). Developing biodiversity indicators as a tool for regulating development activities in and around protected areas in the North West Province of Cameroon. CBBIA final report (http://www3.webng.com/jerbarker/home/eiatoolkit/downloads/PAPreports/CameroonPAPreport.pdfaccess ed $20 / 01 / 2021$ ).

[17] UNCCD. (2013). Progress indicators adopted by the United Nations Convention to Combat Desertification (UNCCD) at their $11^{\text {th }}$ conference of the parties. http://www.unccd.int/lists/officialdocuments/cop11/23add1 en g.pdf. Accessed on the $26^{\text {th }}$ December 2019.

[18] Ndenecho, N. E. (2005). The Savanization of Tropical Montane Cloud Forests in the Bamenda Highlands, Cameroon. Journal of the Cameroon Academy of Sciences, 5 (1), 3-10.

[19] Kometa, S. S., and Tambe, M. A. (2012). Watershed Degradation in the Bamendjin Area of the North West Region of Cameroon and Its Implication for Development. Journal of Sustainable Development, 5 (9), 75-84.

[20] Achankeng, E. and Fokeng, M. R. (2015). "Montane Forest Loss and Watershed Degradation: Case of the Tubah Uplands of the North West Region of Cameroon". African Journal of Special Education, 3 (1), 16.

[21] Fogwe, Z. N. and Kwei, J. (2015). Cameroonian protected Kilium-Ijim forests for the development of Oku forest fringe community. Journal of Environmental Research and Management, 6 (5), 293-303.

[22] Temgoua, L., Ajonina, G., Woyu, H. (2018). Land Use and Land Cover Change Analysis in Ajei Upland Watershed Community Forest, North West Region, Cameroon. Journal of Geoscience and Environment Protection, 6, 83-99. doi: 10.4236/gep.2018.69007.

[23] Kometa, C. G. (2019). Drivers of Watershed Degradation and its Implications on Potable Water Supply in the Menchum River Basin of Cameroon. World Journal of Social Science Research. 6 (4), 483-502.

[24] Tume, S. J. P. Kimengsi, J. N., Fogwe, Z. N. (2019). Indigenous Knowledge and Farmer Perceptions of Climate and Ecological Changes in the Bamenda Highlands of Cameroon: Insights from the Bui Plateau. Climate, 7, 138. https://doi.org/10.3390/cli7120138.

[25] Sop, S. M. D., Ngum, T. M., Kemadjou, M. D. L. (2019). Commercialization of Fuel Wood in Bamenda II Subdivision, North West Region of Cameroon. International Journal of Research and Innovation in Social Science (IJRISS), (III), VIII, 314-322.

[26] Atyi, R. E., Ngouhouo P. J., Mvondo A. J-P., Ngoungoure, A., Kankeu, S. R. (2016). Economic and social importance of fuelwood in Cameroon. International Forestry Review, (18), Supplement 1: Special Issue: Valuing the Cameroonian Forest, $52-65$.

[27] Fokeng, M. R. and Meli M. V. (2015). Modelling drivers of forest cover change in the Santchou Wildlife Reserve, West Cameroon using remote sensing and land use dynamic degree indexes. Canadian Journal of Tropical Geography, 2 (2), 2942.

[28] Mbanga, L. A. and Gonne, B. (2013). "Rethinking biodiversity conservation strategies: an analysis of transhumance and grazing in the Benue, Faro, Bouba Ndjidda Complex, (FBBNC) in the North region of Cameroon". Annals of the Faculty of Arts, Letters and Social Sciences 15 (1), 246-292.

[29] Cochrane, M. A., Alencar, A., Schulze, M. D., Souza, C. M., Nepstad, D. C., Lefebvre, P., Davidson E. A., (1999). Positive feedbacks in the fire dynamic of closed canopy tropical forests. Science, 284, 1832-1835.

[30] Skole, D. and Tucker, C., (1993). Tropical deforestation and habitat fragmentation in the Amazon. Sciences, 260 (5116), 1905-1910.

[31] Souza, C. M., Roberts, D. A., Cochrane, M. A., (2005). Combining spectral and spatial information to map canopy damage from selective logging and forest fires. Remote Sensing of Environment, 98, 329-343. 